\title{
ЭКОНОМИКО-МАТЕМАТИЧЕСКАЯ МОДЕЛЬ УПРАВЛЕНИЯ РИСКАМИ ПРИ КОМПЛЕКСНОМ ОСВОЕНИИ ТЕРРИТОРИИ
}

\author{
С.В. БАБЕНКО \\ Г.В. БАБЕНКО \\ Санкт- Петербургский государственный университет сервиса и экономики \\ (СПбГУСЭ), 191018, Санкт- Петербург, ул. Кавалергардская, 7
}

\begin{abstract}
Аннотация:
Выполнение инвестиционно-строительных проектов комплексного освоения территории в городской агломерации происходит в условиях воздействия разнообразных рисков. В статье предложена экономико-математическая модель управления рисками при их реализации. Программа «Управление рисками при строительстве (реконструкции) объектов, входящих в проекты комплексного освоения территории в городской агломерации», разработанная на основе предложенного алгоритма, позволит органам управления процессом строительства (реконструкции) зданий реализовать ее на практике.

Ключевые слова. Классификация рисков, имитационная модель, экспертный метод
\end{abstract}

\section{ВВЕДЕНИЕ}

Инвестиционный проект комплексного освоения территории в городской агломерации представляет собой систему, которая образована из большого количества элементов, взаимодействующих друг с другом и с внешней средой. Характер этого взаимодействия достаточно сложен и не всегда полно и достоверно известен всем участникам проекта: условия внешнего и внутреннего окружения проекта непрерывно изменяются, в каждом из элементов проекта могут произойти разнообразные непредвиденные события, связанные с возможностью возникновения неблагоприятных ситуаций, которые могут привести к негативным последствиям для всех или отдельных участников проекта. Учет данных особенностей закономерно обуславливает то, что риски являются объективными постоянно действующими факторами на стадии разработки и реализации проектов реконструкции объектов, поэтому их оценка является одной из важных задач.

Основоположниками идей оценки и диагностики рисков, а также управления рисками признано считать зарубежных исследователей - А. Смита, А.Х. Уиллета, Ф. Найта, Г. Марковица, Е.Ф. Бригема, В. Фальцмана, У. Джека, О. Моргенштерна, Дж. Фон Неймана, Ф. Блэка, и др.

Следует отметить, что в методике различаются понятия «риск»и «неопределенность». Понятие риск связано с такими ситуациями, в которых может быть оценено наступление неблагоприятных событий с определенной степенью вероятности. Ситуации, при которых невозможно установить вероятность про- 
явления различных событий и предвидеть способы устранения их негативных последствий, называют ситуациями неопределенности.

\section{РЕЗУЛЬТАТЫ И ИХ ОБСУЖДЕНИЕ}

Возникновение рисков связано с влиянием внешних и внутренних факторов (причин) возникновения рисков.

Под факторами (причинами) возникновения рисков автор понимает незапланированные события, которые могут осуществиться с определенной степенью вероятности и оказать отрицательное воздействие на процесс разработки и реализации проекта комплексного освоения территории [1].

Классификация рисков и факторов (причин) их возникновения является основой для их оценки (табл. 1).

Таблица 1 - Классификация рисков при комплексном освоении территории в городской агломерации

\begin{tabular}{|c|c|}
\hline a.i.1. $\quad$ Группы рисков & Причины возникновения рисков \\
\hline 1. Политические & $\begin{array}{l}\text { 1.1. недостатки в работе органов законодательной власти; } \\
\text { 1.2. то же исполнительной власти }\end{array}$ \\
\hline $\begin{array}{l}2 . \quad \text { Финансово- } \\
\text { экономические }\end{array}$ & $\begin{array}{l}\text { 2.1. колебания рыночной конъюнктуры, цен, валютных курсов; } \\
\text { 2.2. инфляция; } \\
\text { 2.3. недостоверная информация о финансовом положении и деловой } \\
\text { репутации предприятий-участников (возможность неплатежей, сры- } \\
\text { вов договорных обязательств и т.п.); } \\
\text { 2.4. недостаточное финансирование проекта; } \\
\text { 2.5. неполнота или неточность экономических расчетов при технико- } \\
\text { экономического обосновании проектных решений }\end{array}$ \\
\hline 3. Технические & $\begin{array}{l}\text { 5.1. ошибки в проектно-сметной документации; } \\
\text { 5.2. недостаточный уровень применения технологий компьютерного } \\
\text { проектирования; } \\
\text { 5.3. низкий уровень применения ресурсосберегающих технологий; } \\
\text { 5.4. неквалифицированные исполнители; } \\
\text { 5.5. несвоевременная поставка материалов, машин и оборудования } \\
\text { при реализации проекта; } \\
\text { 5.6. отказ оборудования; } \\
\text { 5.7. повреждение строительных конструкций и инженерных сетей } \\
\text { при реализации проекта }\end{array}$ \\
\hline $\begin{array}{l}4 . \quad \text { Организационо- } \\
\text { технологические }\end{array}$ & $\begin{array}{l}\text { 4.1. нарушение сроков выполнения работ; } \\
\text { 4.2. недостаточный уровень применения современных технологий } \\
\text { при разработке проектов }\end{array}$ \\
\hline 5. Социальные & $\begin{array}{l}\text { 3.1. коррупция; } \\
\text { 3.2. этнические и религиозные конфликты; } \\
\text { 3.3. вандализм, терроризм, саботаж; } \\
\text { 3.4. безработица }\end{array}$ \\
\hline 6. Правовые & $\begin{array}{l}\text { 7.1. недостатки законодательной базы; } \\
\text { 7.2. нарушение договорных обязательств; } \\
\text { 7.3. неправильное оформление юридических прав собственности на } \\
\text { земельный участок, разрешения на реконструкцию и строительство }\end{array}$ \\
\hline 7. Экологические & $\begin{array}{l}\text { 6.1. неблагоприятная экологическая обстановка (загрязнение атмо- } \\
\text { сферы, почвы, воды); } \\
\text { 6.2. природные катаклизмы (наводнения, ураганы и др.) }\end{array}$ \\
\hline
\end{tabular}


Рассмотрим основные методы, рекомендуемые международной и отечественной практикой для оценки рисков.

Статистический метод оценки рисков основан на применении аппарата математической статистики. В основе его лежит измерение таких параметров рискового события, как дисперсия, среднеквадратическое отклонение, коэффициенты вариации и корреляции. Основным недостатком этого метода являются громоздкие вычисления значений среднеквадратического отклонения результирующих показателей.

Метод экспертных оценок представляет собой комплекс логических и математических процедур, направленных на получение заключения эксперта по определенному кругу вопросов. Главным его преимуществом является возможность использования для выбора оптимальных проектных решений опыта и интуиции компетентного специалиста [2]. Применение этого метода может быть затруднено привлечением независимых, компетентных экспертов и субъективностью оценок. 
Рис. 1 - Имитационная модель управления рисками при реализации проектов комплексного освоения территории в городской агломерации (начало)

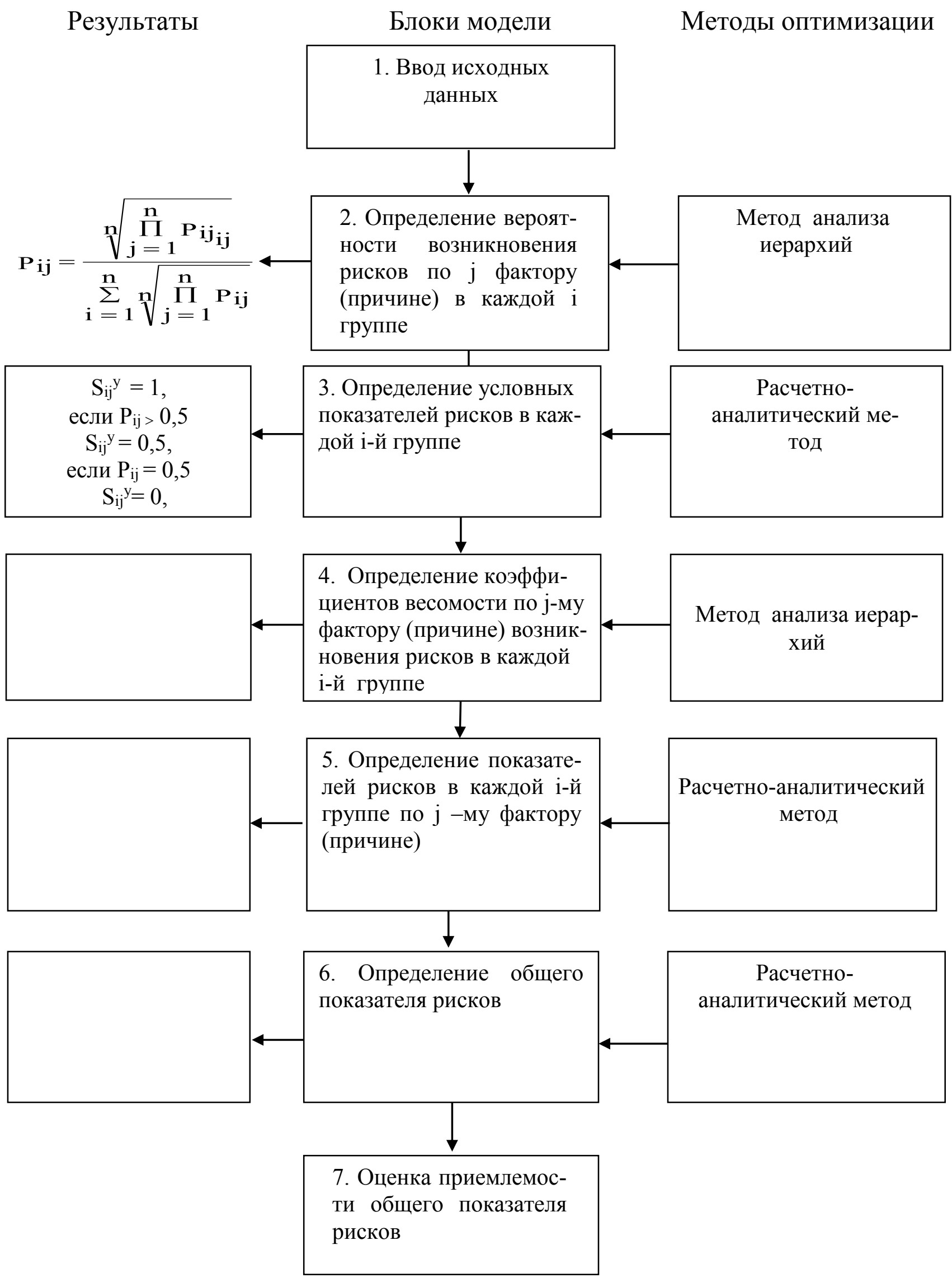


Рис. 1 - Имитационная модель управления рисками при реализации проектов комплексного освоения территории в городской агломерации (продолжение)
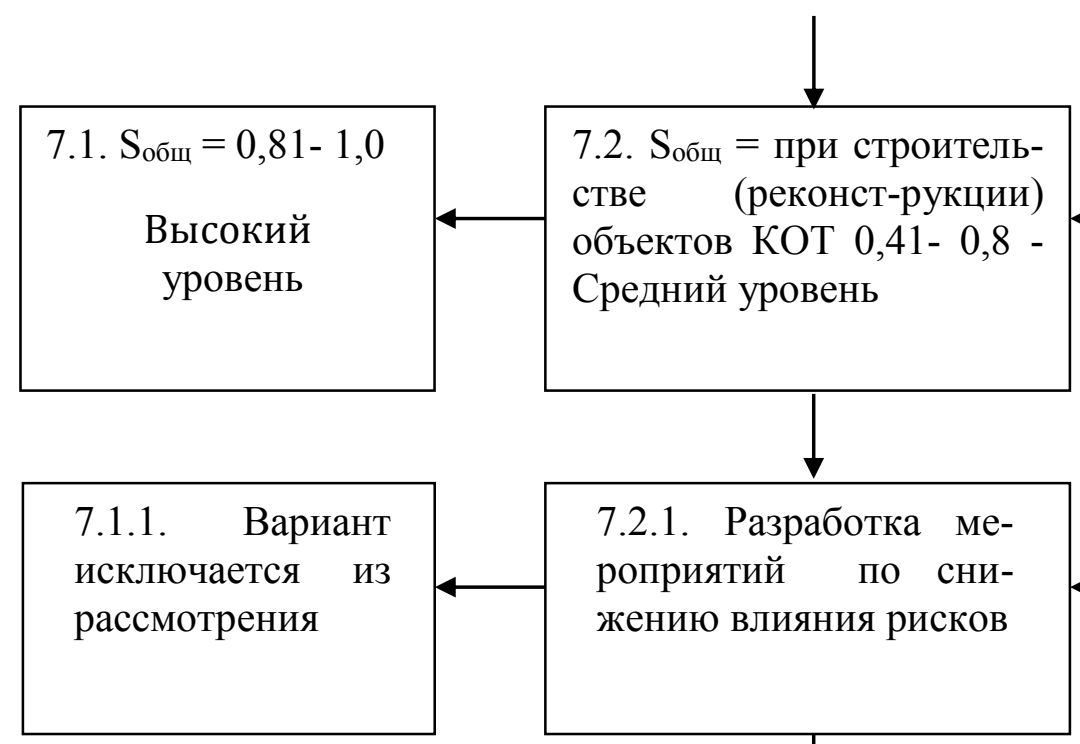

7.2.1. Разработка мероприятий по снижению влияния рисков 7.3. $\mathrm{S}_{\text {общ }}=0-0,4$ Низкий уровень

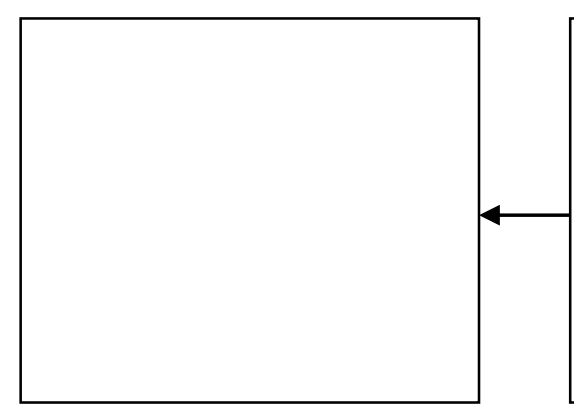

a) Определение вероятности осуществления ј-го мероприятия по снижению влияния рисков в каждой i-й группе

$$
\begin{gathered}
Z_{\mathrm{ij}}^{\mathrm{y}}=1, \\
\text { если } \mathrm{P}_{\mathrm{ij}}>0,5 \\
\mathrm{Z}_{\mathrm{ij}}^{\mathrm{y}}=0,5, \\
\text { если } \mathrm{P}_{\mathrm{ij}}=0,5 \\
\mathrm{Z}_{\mathrm{ij}} \mathrm{y}^{\mathrm{y}}=0, \\
\text { если } \mathrm{P}_{\mathrm{ij}}<0,5
\end{gathered}
$$

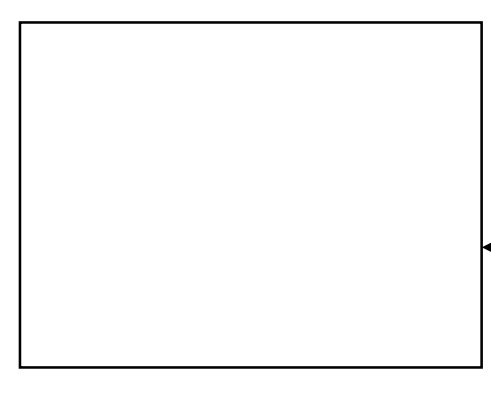

б) Определение условного показателя снижения рисков от $\mathrm{j}$-го мероприятия в каждой i-й группе

7.3.1. Вариант рекомендуется для дальнейшего рассмотрения

Метод анализа иерархий

Расчетноаналитический метод

Метод анализа иерархий 
Рис. 1 - Имитационная модель управления рисками при реализации проектов комплексного освоения территории в городской агломерации (окончание)

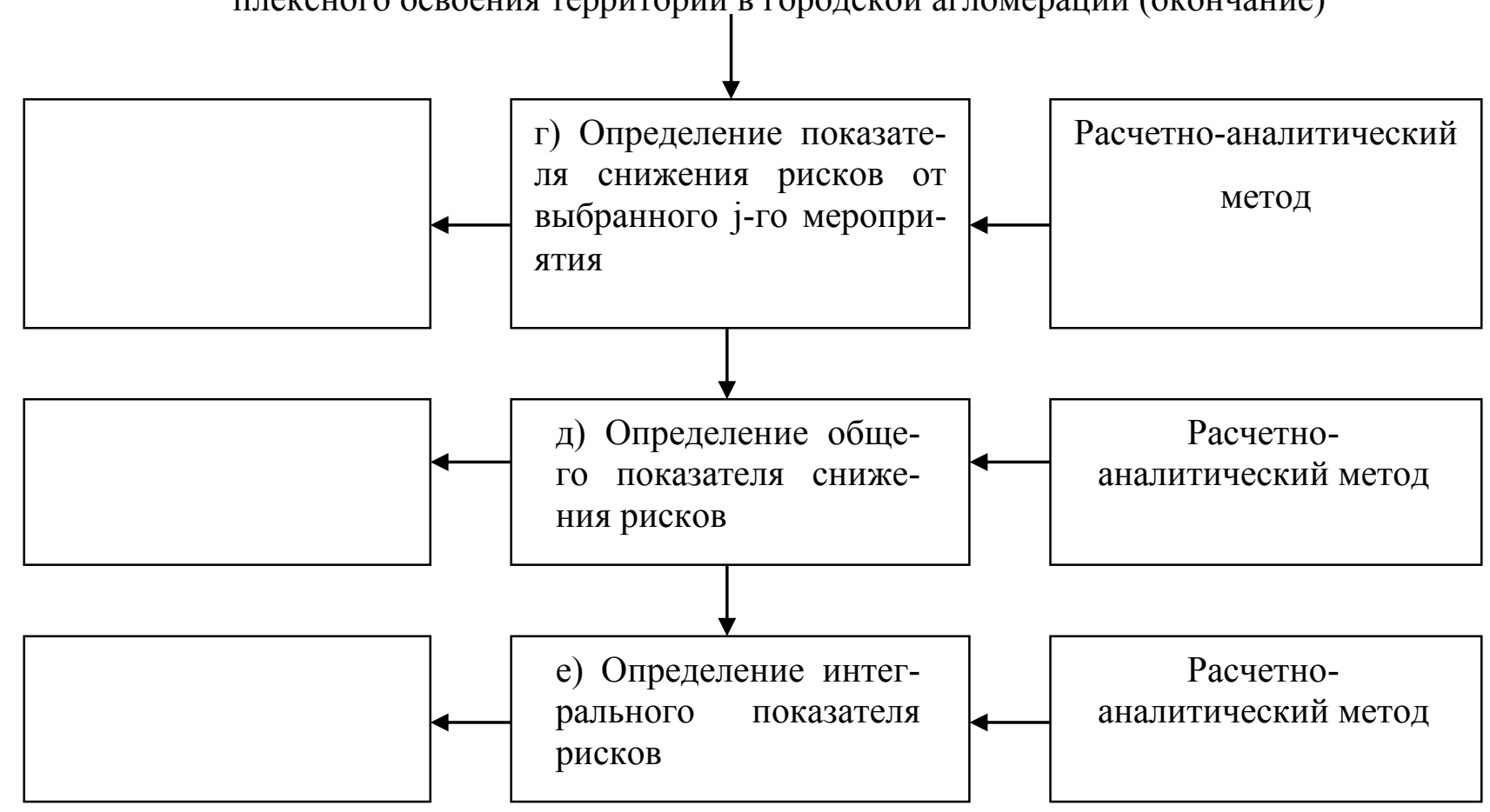

Метод «дерева решений» используется для оценки рисков проекта, имеющего ограниченное число вариантов исхода событий. Он применяется в тех случаях, когда принимаемое решение на текущем этапе существенно зависит от результатов предыдущего. Основным его недостатком является резкое возрастание объема вычислений при переборе возможных вариантов.

В основе анализе вероятностных распределений денежных потоков лежит измерение математического ожидания и стандартного отклонения чистого дисконтированного дохода инвестиционного проекта на основании прогнозной величины и распределения вероятностей текущего сальдо денежных потоков. Ocновным недостатком этого метода является его высокий субъективизм.

На основе анализа методов оценки рисков автором разработана имитационная модель управления рисками при реализации проектов комплексного освоения территории в городской агломерации (рис. 1).

Для определения вероятности возникновения факторов (причин) рисков автор использовал метод анализа иерархий Т. Саати. Для этого было создано две группы экспертов по 10 человек, в состав которых вошли:

специалисты проектных организаций в области проектирования объектов, входящих в проект комплексного освоения территории в мегаполисе;

специалисты организаций, осуществляющих техническую эксплуатацию объектов, входящих в проект комплексного освоения территории в мегаполисе;

работники НИИ, осуществляющие разработки новых технологий строительства объектов, входящих в проект комплексного освоения территории в мегаполисе; 
специалисты инвестиционных и строительных компаний, осуществляющие строительство объектов, входящих в проект комплексного освоения территории в мегаполисе.

Достоверность результатов экспертной оценки зависит от количества привлекаемых специалистов и их компетентности, которая, в свою очередь, определяется такими качествами экспертов, как информированность, креативность, конформизм, конструктивность, аналитичность, широта мышления, самокритичность, интуиция и др. Существует множество методов определения компетентности привлекаемых экспертов, самыми распространенными являются самооценка и оценка другими экспертами.

Коэффициенты весомости факторов (причин) возникновения рисков по их видам $\left(\mathrm{F}_{\mathrm{i}}\right)$ и по каждому фактору (причине) каждого вида $\left(\mathrm{F}_{\mathrm{ij}}\right)$ определяются экспертами путем открытого группового обсуждения по 9-балльной шкале оценок, которые переводятся затем в относительные единицы.

Согласно теории квалиметрии значения коэффициентов весомости должны соответствовать следующим условиям: $0 \square \mathrm{F}_{\mathrm{i}} \square 1,0 \square \mathrm{F}_{\mathrm{ij}} \square 1$.

Алгоритм применения метода анализа иерархий при оценке эффективности представлен во второй главе диссертации.

Результаты расчетов коэффициентов весомости факторов (причин) возникновения рисков по их видам $\left(\mathrm{F}_{\mathrm{i}}\right)$ и по каждому фактору (причине) каждого вида $\left(\mathrm{F}_{\mathrm{ij}}\right)$ приведены в табл. 2. 
Таблица 2 - Коэффициенты весомости факторов (причин) возникновения рисков

\begin{tabular}{|c|c|c|c|}
\hline $\begin{array}{l}\text { а.і.3. Группы } \\
\text { факторов } \\
\text { (причин) } \\
\text { возникновения } \\
\text { рисков }\end{array}$ & $\begin{array}{l}\text { а.i.4. } \\
\text { начения } \\
\text { коэффицие } \\
\text { нтов } \\
\text { весомости } \\
\text { групп } \\
\text { факторов } \\
\text { (причин) } \\
\text { возникнове } \\
\text { ния рисков }\end{array}$ & $\begin{array}{lll}\text { a.i.5. } & \text { Факторы } \\
\text { рисков } & & \text { (причины) } \\
\end{array}$ & $\begin{array}{l}\text { а.i.6. Знач } \\
\text { ения } \\
\text { коэффициенто } \\
\text { в весомости } \\
\text { факторов } \\
\text { (причин) } \\
\text { а.i.7. возн } \\
\text { икновения } \\
\text { рисков в в } \\
\text { каждой группе }\end{array}$ \\
\hline 1. Политические & $\mathrm{F}_{\mathrm{in}}=0,10$ & $\begin{array}{l}\text { 1.1. недостатки в работе органов законодательной } \\
\text { власти; } \\
\text { 1.2. то же исполнительной власти }\end{array}$ & $\begin{array}{l}0,4 \\
0,6 \\
\end{array}$ \\
\hline $\begin{array}{l}2 . \text { Финансово- } \\
\text { экономические }\end{array}$ & $\mathrm{F}_{\mathrm{i \phi}}=0,30$ & $\begin{array}{l}\text { 2.1. колебания рыночной конъюнктуры, цен, ва- } \\
\text { лютных курсов; } \\
\text { 2.2. инфляция; } \\
\text { 2.3. недостоверная информация о финансовом по- } \\
\text { ложении и деловой репутации предприятий- } \\
\text { участников (возможность неплатежей, срывов до- } \\
\text { говорных обязательств и т.п.); } \\
\text { 2.4. недостаточное финансирование проекта; } \\
\text { 2.5. неполнота или неточность экономических } \\
\text { расчетов при технико-экономическом обо-сновании } \\
\text { проектных решений }\end{array}$ & $\begin{array}{l}0,22 \\
0,25\end{array}$ \\
\hline 3. Технические & $\mathrm{F}_{\mathrm{iT}}=0,15$ & $\begin{array}{l}\text { 5.1. ошибки в проектно-сметной документации; } \\
\text { 5.2. недостаточный уровень применения техноло- } \\
\text { гий компьютерного проектирования; } \\
\text { 5.3. низкий уровень применения ресурсосберегаю- } \\
\text { щих технологий; } \\
\text { 5.4. неквалифицированные исполнители; } \\
\text { 5.5. несвоевременная поставка материалов, машин } \\
\text { и оборудования при реализации проекта; } \\
\text { 5.6. отказ оборудования; } \\
\text { 5.7. повреждение строительных конструкций и } \\
\text { инженерных сетей при реконструкции жилых } \\
\text { домов }\end{array}$ & $\begin{array}{l}0,10 \\
0,25 \\
0,2 \\
0,1 \\
0,20 \\
0,11\end{array}$ \\
\hline $\begin{array}{l}4 . \quad \text { Оргни- } \\
\text { зационно- } \\
\text { технологические }\end{array}$ & $\mathrm{F}_{\mathrm{io}}=0,20$ & $\begin{array}{l}\text { 4.1. нарушение сроков выполнения работ; } \\
\text { 4.2. } \quad \text { недостаточный } \quad \text { уровень применения } \\
\text { современных технологий при разработке проектов }\end{array}$ & $\begin{array}{l}0,4 \\
0,6\end{array}$ \\
\hline 5. Социальные & $\mathrm{F}_{\mathrm{ic}}=0.05$ & $\begin{array}{l}\text { 3.1. коррупция; } \\
\text { 3.2. этнические и религиозные конфликты; } \\
\text { 3.3. вандализм, терроризм, саботаж; } \\
\text { 3.4. безработица }\end{array}$ & $\begin{array}{l}0,5 \\
0,1 \\
0,1 \\
0,5\end{array}$ \\
\hline 6. Правовые & $\mathrm{F}_{\mathrm{in}}=0,05$ & $\begin{array}{l}\text { 7.1. недостатки законодательной базы; } \\
\text { 7.2. нарушение договорных обя-зательств; } \\
\text { 7.3. неправильное оформление юридических прав: } \\
\text { собственности на земельный участок, разрешения } \\
\text { на реконструкцию, снос и строительство объектов }\end{array}$ & $\begin{array}{l}0,4 \\
0,5\end{array}$ \\
\hline 7. Экологические & $\mathrm{F}_{\mathrm{i} \ni}=0,15$ & $\begin{array}{l}\text { 6.1. неблагоприятная экологичес-кая обстановка } \\
\text { (загрязнение атмос-феры, почвы, воды); } \\
\text { 6.2. природные катаклизмы (навод-нения, ураганы) }\end{array}$ & 0,80 \\
\hline
\end{tabular}

Показатель риска $\left(\mathrm{S}_{\mathrm{j} \sqsubset \mathrm{i}}\right.$ ) по каждому j-му фактору (причине) i-ого вида риска определяются следующим образом:

$$
\mathrm{S}_{\mathbf{i j}}=\mathrm{F}_{\mathbf{i j}} \mathrm{P}_{\mathbf{i j}} \mathrm{S}_{\text {зад. } \mathbf{i j}(1)}
$$


где $F_{i j}$ - коэффициент весомости ј-ого фактора (причины) возникновения риска і-го вида;

$\mathrm{P}_{\mathrm{ij}}-$ вероятность возникновения риска i-го вида под влиянием $\mathrm{j}$-го фактора (причины);

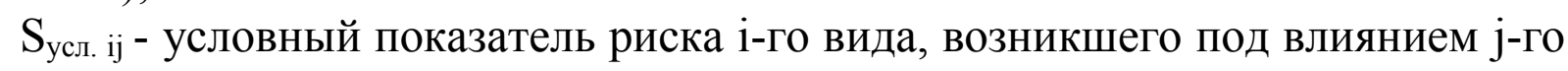
фактора (причины).

a.i.7.a. Значение условного показателя риска і-го вида, возникшего под влиянием ј-го фактора (причины) определяется согласно следующим соотношениям:

$$
\begin{aligned}
& \mathrm{S}_{\text {зад. ij }}=1, \text { если } \mathrm{P}_{\mathrm{ij}} \square 0,5 \\
& \mathrm{~S}_{\text {зад. ij }}=0,5, \text { если } \mathrm{P}_{\mathrm{ij}}=0,5(2) \\
& \mathrm{S}_{\text {зад. ij }}=0, \text { если } \mathrm{P}_{\mathrm{ij}} \square 0,5
\end{aligned}
$$

Показатель проектных рисков $\left(\mathrm{S}_{\mathrm{i}}\right)$ по каждому i-му виду определяется следующим образом:

$$
\mathbf{S}_{\mathbf{i}}=\sum_{\mathbf{j}=1}^{\sum_{\mathbf{i j}}} \mathbf{S}_{\mathbf{i j}}
$$

где $\mathrm{j}=1,2, \ldots, \mathrm{k}_{\mathrm{j}}$ - количество факторов (причин) возникновения рисков $\mathrm{i}-$ го вида.

Общий показатель рисков $\left(\mathrm{S}_{\text {общ}}\right)$ определяется по следующей формуле:

$$
\begin{aligned}
& \mathrm{S}_{\text {обш }}=\sum_{\mathrm{i}=1}^{\mathrm{mi}_{\mathrm{i}}} \\
& \text { при } \\
& \sum_{\mathrm{m}=1}^{\mathrm{m}_{\mathrm{i}}} \mathrm{F}_{\mathrm{i}}=1
\end{aligned}
$$

Далее осуществляется оценка приемлемости общего показателя рисков по следующей схеме:

0 - 0,4- низкий уровень;

$0,41-0,8-$ средний уровень;

0,81 - 1,0 - высокий уровень.

Варианты с высоким уровнем влияния рисков исключаются из рассмотрения в числе других альтернативных вариантов, так как разработка мероприятий по их снижению требует значительных затрат. Для вариантов со средним уровнем влияния рисков разрабатываются мероприятия по их снижению, которые при незначительных затратах существенно снижают риск [3].

Для каждого вида мероприятий по снижению риска і-го вида определяются коэффициенты весомости по той же методике, что и коэффициенты весомости факторов (причин) возникновения рисков (табл. 3). 
Таблица 3 -Значения коэффициентов весомости мероприятий по снижению рисков

\begin{tabular}{|l|l|l|}
\hline $\begin{array}{c}\text { № } \\
\text { п/п }\end{array}$ & \multicolumn{1}{|c|}{ Наименование мероприятия } & \multicolumn{1}{|c|}{$\begin{array}{c}\text { Значения } \\
\text { коэффициентов } \\
\text { весомости }\end{array}$} \\
\hline 1. & $\begin{array}{l}\text { Создание специального резервного фонда проекта для покрытия } \\
\text { возможных убытков - самострахование }\end{array}$ & 0,5 \\
\hline 2. & Проведение дополнительной технической экспертизы проекта & 0,10 \\
\hline 3. & Страхование проектных рисков & 0,14 \\
\hline 4. & Установление юридической ответственности участников проекта & 0,05 \\
\hline 5. & Прогнозирование непредвиденых событий & 0,15 \\
\hline 6. & Проведение мониторинга & 0,05 \\
\hline 7. & Контроль за ходом реализации проекта & 0,01 \\
\hline
\end{tabular}

Показатель снижения рисков і-го вида по каждому ј-му фактору (причине) от проводимого j-го мероприятия $\left(\mathrm{Z}_{\mathrm{ji}}\right)$ определяется следующим образом:

a.ii.

$$
Z_{j i}=F_{\mathbf{i j}}^{m} P_{\mathbf{i j}} Z_{\text {зад.jj }}
$$

где $\mathrm{F}^{\mathrm{m}}{ }_{\mathrm{ij}}$ - коэффициент весомости $\mathrm{j}$-го мероприятия по снижению рисков $\mathrm{i}$ го вида;

$\mathrm{P}_{\mathrm{ij}}$ - вероятность осуществления j-го мероприятия по снижению рисков $\mathrm{i}$-го вида;

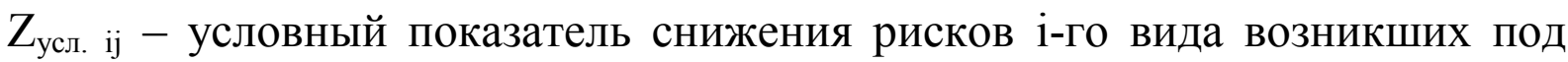
влиянием ј-го фактора (причины).

7. Показатель снижения рисков по каждому i-му виду от всех мероприятий $\left(Z_{\mathrm{i}}\right)$ определяется по формуле:

$$
\boldsymbol{z}_{\mathbf{i}}=\sum_{\mathbf{i}}^{\mathbf{k}} \boldsymbol{z}_{\mathbf{j}}
$$

где $\mathrm{i}=1,2, \ldots, \mathrm{k}$ - количество мер в i-й группе.

Общий показатель снижения рисков $\left(\mathrm{Z}_{\text {общ. }}\right)$ определяется по следующей формуле:

$$
\mathrm{Z}_{\text {общ }}=\sum_{\mathbf{i}=1}^{\mathrm{m}} \mathrm{Z}_{\mathbf{i}}
$$

где $\mathrm{i}=1,2, \ldots, \mathrm{m}$ - количество видов мероприятий по снижению рисков.

Интегральный показатель рисков с учетом реализации мероприятий по снижению их влияния определяется по следующей формуле:

$$
\mathrm{I}_{\mathbf{о б ш}}=\mathrm{S}_{\text {общ}}-\mathrm{Z}_{\mathbf{о}} \text { бщ(9) }
$$

Мероприятия по снижению рисков считаются достигнутыми, если выполняется следующее условие:

$$
\mathrm{I}_{\mathrm{O}} \text { бщ } \leq \text { o,5 (10) }
$$

\section{ВЫВОДЫ}

В соответствии с предложенным алгоритмом целесообразно разработать программу «Управление рисками при строительстве (реконструкции) объектов, входящих в проекты комплексного освоения территории в городской агломера- 
ции», позволяющую органам управления процессом строительства (реконструкции) зданий реализовать ее на практике.

\section{ЛИТЕРАТУРА}

1. Бачкаи Т., Месена Д. Хозяйственный риск и методы его измерения. М. - 1999. - С. 364

2. Колганов М.. Особенности предпринимательства в переходной экономике// Экономист 2004, №1, с. 77 - 82.

3. Эффективность реконструкции жилых зданий [эл.ресурс]/ Режим доступа: http://www.mirrabot.com/subjects/subject_9546503.html 